\title{
UV-VIS, Surface Morphology and Electrochemical Study of Cobalt Electrodeposition from Choline Chloride-ethylene Glycol Liquid Mixture
}

\author{
Jamil A. Juma ${ }^{1}$, Wrya O. Karim², Shujahadeen B Aziz ${ }^{3 *}$ \\ ${ }^{1}$ Department of Chemistry, Faculty of Science and Health, Koya University, Koya KOY45, Kurdistan \\ Region - F.R. Iraq, \\ ${ }^{2}$ Chemistry Department, College of Science, University of Sulaimani, Qliasan Street, Sulaimani City, \\ 46002, Kurdistan, Iraq, \\ ${ }^{3}$ Hameed Majid Advanced Polymeric Materials Research Lab., Physics Department, College of \\ Science, University of Sulaimani, Qlyasan Street, Sulaimani 46001, Kurdistan Regional Government, \\ Iraq. \\ *E-mail: shujahadeenaziz@gmail.com
}

Received: 28 May 2021 / Accepted: 1 July 2021 / Published: 10 September 2021

In this report, we present a simple, efficient and promising methodology of electroplating cobalt in the mixture of choline chloride and ethylene glycol in 1:2 mol ratio in the presence of hydantoin (HD) as an additive. The bulk electroplating was carried out at a constant current density of $2.8 \mathrm{~mA} \mathrm{~cm}{ }^{-2}$ for one hour and at $90{ }^{\circ} \mathrm{C}$. A range of electrochemical, spectroscopic and microscopic techniques were used in the characterizations of the mechanism and thick film formed from electroplating processes of copper coated by cobalt. The film thickness of Co was calculated and found to be 8.31 and $23.54 \mu \mathrm{m}$ in the absence and presence of hydantoin, respectively. The hardness test indicates the dense Co film formation on copper sheet. The mirror-like Co film will be shown using SEM and photograph.

Keyword: Mirror finishing, hydantoin, cobalt, deep eutectic solvent, UV-vis study; Morphology; Electrochemical analysis

\section{$\underline{\text { FULL TEXT }}$}

(C) 2021 The Authors. Published by ESG (www.electrochemsci.org). This article is an open access article distributed under the terms and conditions of the Creative Commons Attribution license (http://creativecommons.org/licenses/by/4.0/). 